\title{
High-Strength Low-Alloy (HSLA) Mg-Zn-Ca Alloys with Excellent Biodegradation Performance
}

\section{Journal Article}

Author(s):

Löffler, Jörg F.; Hofstetter, Joëlle; Becker, Michael; Martinelli, Elisabeth; Weinberg, Annelie M.; Mingler, Bernhard; Kilian, Helmut; Pogatscher, Stefan; Uggowitzer, Peter (D)

Publication date:

2014-04

Permanent link:

https://doi.org/10.3929/ethz-b-000080650

Rights / license:

In Copyright - Non-Commercial Use Permitted

Originally published in:

JOM 66(4), https://doi.org/10.1007/s11837-014-0875-5 


\title{
High-Strength Low-Alloy (HSLA) Mg-Zn-Ca Alloys with Excellent Biodegradation Performance
}

\author{
J. HOFSTETTER,${ }^{1}$ M. BECKER,${ }^{1}$ E. MARTINELLI,${ }^{2}$ A.M. WEINBERG,${ }^{2}$ \\ B. MINGLER ${ }^{3}$ H. KILIAN, ${ }^{4}$ S. POGATSCHER, ${ }^{1}$ P.J. UGGOWITZER, ${ }^{1}$ \\ and J.F. LÖFFLER ${ }^{1,5}$
}

\begin{abstract}
1.-Laboratory of Metal Physics and Technology, Department of Materials, ETH Zurich, 8093 Zurich, Switzerland. 2.-Department of Orthopedics, Medical University Graz, 8036 Graz, Austria. 3.-Health \& Environment Department, AIT Austrian Institute of Technology GmbH, Biomedical Systems, 2700 Wr. Neustadt, Austria. 4.-Department of Mobility, AIT Austrian Institute of Technology GmbH, Light Metals Technologies, LKR, 5282 Ranshofen, Austria. 5.—e-mail: joerg.loeffler@mat.ethz.ch
\end{abstract}

This article deals with the development of fine-grained high-strength low-alloy (HSLA) magnesium alloys intended for use as biodegradable implant material. The alloys contain solely low amounts of $\mathrm{Zn}$ and $\mathrm{Ca}$ as alloying elements. We illustrate the development path starting from the high-Zn-containing ZX50 (MgZn5Ca0.25) alloy with conventional purity, to an ultrahigh-purity ZX50 modification, and further to the ultrahigh-purity Zn-lean alloy ZX10 (MgZn1Ca0.3). It is shown that alloys with high $\mathrm{Zn}$-content are prone to biocorrosion in various environments, most probably because of the presence of the intermetallic phase $\mathrm{Mg}_{6} \mathrm{Zn}_{3} \mathrm{Ca}_{2}$. A reduction of the $\mathrm{Zn}$ content results in $(\mathrm{Mg}, \mathrm{Zn})_{2} \mathrm{Ca}$ phase formation. This phase is less noble than the Mg-matrix and therefore, in contrast to $\mathrm{Mg}_{6} \mathrm{Zn}_{3} \mathrm{Ca}_{2}$, does not act as cathodic site. A finegrained microstructure is achieved by the controlled formation of fine and homogeneously distributed $(\mathrm{Mg}, \mathrm{Zn})_{2} \mathrm{Ca}$ precipitates, which influence dynamic recrystallization and grain growth during hot forming. Such design scheme is comparable to that of HSLA steels, where low amounts of alloying elements are intended to produce a very fine dispersion of particles to increase the material's strength by refining the grain size. Consequently our new, ultrapure ZX10 alloy exhibits high strength (yield strength $R_{\mathrm{p}}=240 \mathrm{MPa}$, ultimate tensile strength $R_{\mathrm{m}}=255 \mathrm{MPa}$ ) and simultaneously high ductility (elongation to fracture $A=27 \%$ ), as well as low mechanical anisotropy. Because of the anodic nature of the $(\mathrm{Mg}, \mathrm{Zn})_{2} \mathrm{Ca}$ particles used in the HSLA concept, the in vivo degradation in a rat femur implantation study is very slow and homogeneous without clinically observable hydrogen evolution, making the ZX10 alloy a promising material for biodegradable implants.

\section{INTRODUCTION}

Magnesium $(\mathrm{Mg})$ and its alloys are biocompatible and biodegradable, and thus, these materials are promising for medical applications. ${ }^{1-3}$ For use in such applications, they need to fulfill challenging mechanical, electrochemical, and biological requirements. A recent study has demonstrated that the alloying system $\mathrm{Mg}-\mathrm{Zn}-\mathrm{Ca}$ may offer a very attractive combination of high strength and simultaneously high ductility; $R_{\mathrm{p}}>200 \mathrm{MPa}$,
$R_{\mathrm{m}}>250 \mathrm{MPa}, A>20 \% .^{4}$ From a biochemistry viewpoint, $\mathrm{Zn}$ and $\mathrm{Ca}$ are both essential trace elements in the human body and, as alloying element in $\mathrm{Mg}$, known to positively influence bone healing and cell reactions. ${ }^{5,6}$

The highly favorable mechanical properties of these types of $\mathrm{Mg}$ alloys can primarily be ascribed to their very fine grain size. High strength is achieved by a high degree of grain-boundary strengthening and by solid-solution hardening of $\mathrm{Zn} .^{4,7,8}$ The ductility of fine-grained $\mathrm{Mg}-\mathrm{Zn}-\mathrm{Ca}$ alloys is increased 
by the activation of nonbasal slip induced by compatibility stresses at the grain boundaries. ${ }^{9,10}$ Furthermore, a grain size of less than $5 \mu \mathrm{m}$ does not only improve strength and ductility but also reduces the mechanical anisotropy. ${ }^{4,7,8,11,12}$

The most important prerequisite for achieving ultrafine-grained structures in $\mathrm{Mg}-\mathrm{Zn}-\mathrm{Ca}$ alloys is the presence of intermetallic particles (IMPs) of controlled density and morphology. Because both alloying elements participate in the formation of the grain-refining IMPs and Zn also contributes to solidsolution strengthening, an ideal $\mathrm{Ca}$ and $\mathrm{Zn}$ amount was worked out by Hänzi et al. ${ }^{4}$ to ensure the best possible grain-boundary strengthening and solidsolution hardening. The alloy ZX50 with the composition window $0.2-0.4$ wt.\% $\mathrm{Ca}$ and $5-6 \mathrm{wt} . \% \mathrm{Zn}$ was found to optimally satisfy the requirements for high strength and simultaneously high ductility.

\section{ALLOY ZX50-FROM "HIGH PURITY" TO "ULTRAHIGH PURITY"}

Because of its attractive mechanical properties and absence of rare-earth (RE) elements, a ZX50 alloy with nominally $5 \mathrm{wt} . \% \mathrm{Zn}$ and 0.25 wt.\% $\mathrm{Ca}$ and conventional purity (CP) was selected for a long-term animal study and compared to the REcontaining alloy WZ21. ${ }^{13}$ Figure 1 illustrates the degradation performance 4 weeks after implantation. Obviously, the degradation of the CP ZX50 alloy is significantly higher than that of WZ21. From the weight loss data in Ref. 13 the in vivo degradation rate $P_{\text {iv }}$ can be estimated to be roughly $1.3 \mathrm{~mm} /$ year for CP ZX50 and $0.16 \mathrm{~mm} /$ year for
WZ21. Although the in vivo degradation rate of WZ21 is relatively low, the corresponding hydrogen gas formation $\left(\mathrm{Mg}+2 \mathrm{H}_{2} \mathrm{O} \rightarrow \mathrm{Mg}(\mathrm{OH})_{2}+\mathrm{H}_{2}\right)$ is still too high to be absorbed by the surrounding tissue. This reveals the particular need for further improvement of the degradation performance, but without using $\mathrm{RE}$ additions, nota bene. For more details on the biological concerns regarding $\mathrm{RE}$ elements, see Ref. 14.

Kraus et al. ${ }^{13}$ did not discuss the metal-physical reasons for the high degradation rate of CP ZX50. However, in the current study, we will illustrate that at least two metallurgical aspects are of particular importance: (i) trace elements, in particular iron, exceeding the impurity tolerance limits, which results in the formation of noble Fe-containing intermetallic particles, ${ }^{15}$ and (ii) formation of noble Zn-containing intermetallic particles of type $\mathrm{Mg}_{6} \mathrm{Zn}_{3} \mathrm{Ca}_{2}{ }^{16}$ Both Fe-containing IMPs and $\mathrm{Zn}$ containing IMPs may act as cathodic sites and lead to anodic dissolution of the $\mathrm{Mg}$ matrix.

It is a well-known fact that the impurity elements $\mathrm{Fe}, \mathrm{Cu}, \mathrm{Ni}$ and $\mathrm{Co}$ enhance the saltwater corrosion of $\mathrm{Mg}$ alloys. ${ }^{17}$ The corrosion rates are significantly accelerated when their concentrations exceed certain values. ${ }^{15,18}$ They are particularly harmful because of their low solid solubility and thus can form precipitates, which provide effective cathodic sites even at low concentrations. ${ }^{19,20}$ To check the influence of trace elements on the degradation performance, we prepared ZX50 alloys using high-purity (HP) $\mathrm{Mg}$ and vacuum-distilled ultrahigh purity (XHP) $\mathrm{Mg} .{ }^{21}$ The chemical composition with specific consideration of "harmful" elements is given in
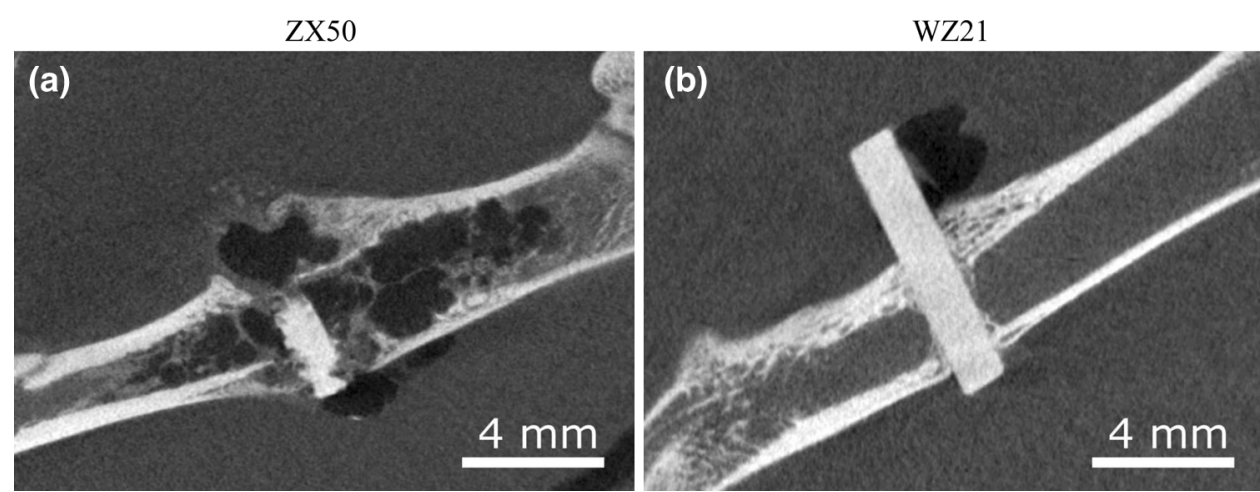

Fig. 1. $\mu \mathrm{CT}$ reconstructions (two-dimensional slices) of Mg-pins implanted into the femur of Sprague-Dawley rats 4 weeks after operation. The degradation rate of the alloy CP ZX50 (a) is more than 3 times higher than that of WZ21 (b). ${ }^{13}$ Massive hydrogen gas formation affects bone and tissue healing for CP ZX50; only moderate hydrogen pocket formation is visible for WZ21.

Table I. Chemical composition of ZX50 with conventional purity (CP), high-purity (HP), and ultra-high purity (XHP)

\begin{tabular}{|c|c|c|c|c|c|c|c|c|}
\hline Alloy & Zn (wt.\%) & Ca (wt.\%) & Mn (ppm) & $\underline{\text { Si (ppm) }}$ & Fe (ppm) & Cu (ppm) & Ni (ppm) & Co (ppm) \\
\hline CP ZX50 & 5.24 & 0.27 & 1630 & 440 & 42 & 9 & 8 & 8 \\
\hline HP ZX50 & 5.21 & 0.29 & 160 & 430 & 31 & 8 & 7 & 5 \\
\hline XHP ZX50 & 5.26 & 0.31 & 0.8 & 2.9 & 0.5 & 0.09 & 0.05 & $<0.05$ \\
\hline
\end{tabular}




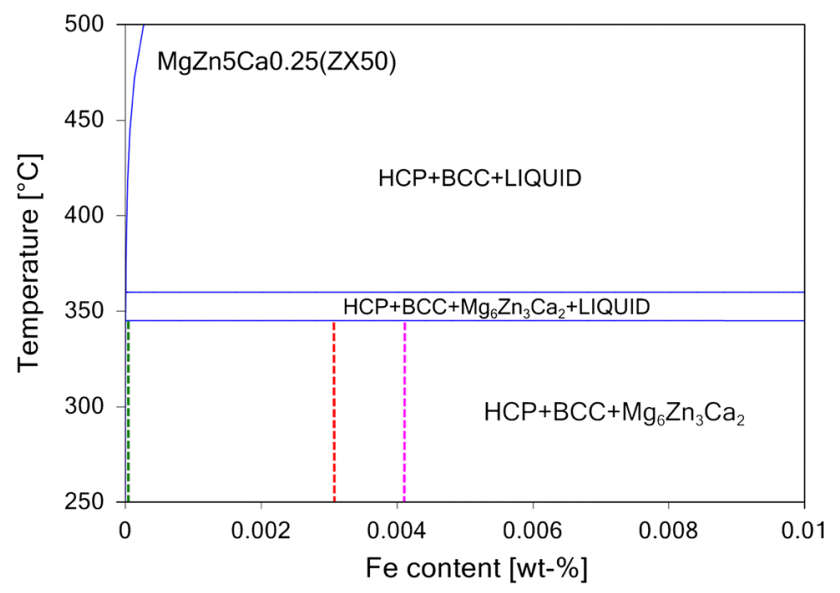

Fig. 2. Isopleth plot of Mg-Zn5-Ca0.25-Fe $<0-0.01>$. The traces of the alloy's constitution points are indicated by the dashed lines; green (XHP ZX50), red (HP ZX50), and magenta (CP ZX50).

Table I. The use of XHP-Mg and ultrapure $\mathrm{Zn}$ and Ca (see the "Methods" section) for the XHP ZX50 synthesis results in a reduction of the trace element content by a factor of about 100 .

Figure 2 shows an isopleth plot of the Mg-Zn5$\mathrm{Ca} 0.25-\mathrm{Fe}$ system calculated using Pandat (CompuTherm, Madison, WI), a simulation software for multicomponent phase diagram calculations. ${ }^{22}$ It can be noted that in solid ZX50, the solubility limit for $\mathrm{Fe}$ is extremely low, i.e., less than $1 \mathrm{ppm} \mathrm{Fe}$. Dashed vertical lines indicate the trace of the constitution points of the three alloys: CP ZX50, HP ZX50, and XHP ZX50. Whereas XHP ZX50 is close to the tolerance limit, the alloys CP ZX50 and HP ZX50 are significantly above the limit, and formation of Fe-containing particles (body-centered cubic [BCC]) will take place. In this respect, it is important to note that, according to experimental findings and thermodynamic simulations, ${ }^{22}$ the BCC phase contains besides $\mathrm{Fe}$ mainly $\mathrm{Mn}$ and $\mathrm{Si}$, and thus, their volume content is dependent not only on the Fe level but also on the Mn and Si content (see Table I). Because the alloys were processed (i.e., extruded to rods) at temperatures of around $300^{\circ} \mathrm{C}$ (see the "Methods" section), we calculated the equilibrium mole fraction of BCC at this temperature. With $3.8 \times 10^{-4} \mathrm{BCC}$ in $\mathrm{CP} \mathrm{ZX} 50$, it is more than one order of magnitude higher than in HP ZX50 $\left(1.6 \times 10^{-5}\right)$ and two orders of magnitude higher than in XHP ZX50 $\left(<1 \times 10^{-6}\right)$.

All three alloys were tested on their corrosion/ degradation behavior in simulated body fluid (SBF). Either carbon dioxide, $\mathrm{CO}_{2}$, or Tris, i.e., tris(hydroxymethyl)aminomethane, $\left(\mathrm{HOCH}_{2}\right)_{3} \mathrm{CNH}_{2}$, was used as buffer. The degradation was measured by the hydrogen evolution method ${ }^{23}$ and evaluated using an improved testing setup. ${ }^{24}$ Figure 3 depicts the mean hydrogen evolution in $\mathrm{CO}_{2}$-buffered $\mathrm{SBF}$ versus time of the ZX50 alloys. The amounts of hydrogen increase steadily at the beginning with a decrease in degradation rate with increasing time.

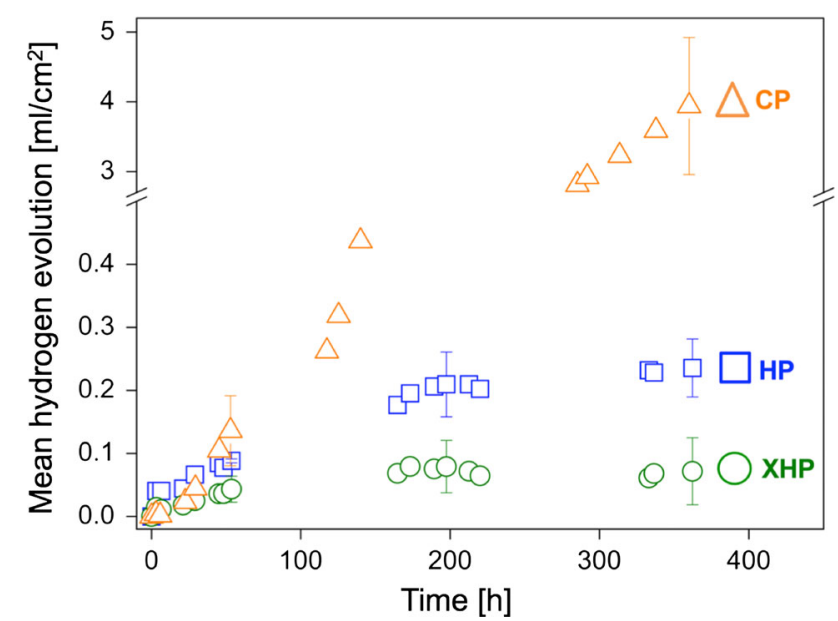

Fig. 3. Mean hydrogen evolution versus time of $\mathrm{CP}, \mathrm{HP}$, and $\mathrm{XHP}$ ZX50 immersed in $\mathrm{CO}_{2}$-buffered SBF with pH 7.45 at $37^{\circ} \mathrm{C}$. (Note the different scales at the $y$-axis; typical data scatter is illustrated by error bars).

As expected, the XHP ZX50 alloy evolves significantly less hydrogen than the $\mathrm{CP}$ and HP alloys within the same time.

This significant improvement (after 2 weeks by more than an order of magnitude from CP to HP, and a factor of $\approx 3$ from HP to XHP) can be attributed to the reduced trace element content below or close to the impurity tolerance limit and the related avoidance of degradation-generating cathodic sites. Very recently, a similar effect of purity was observed by Cao et al. ${ }^{25}$ using unalloyed XHP $\mathrm{Mg}^{21}$ in $3.5 \% \mathrm{NaCl}$ solution. Hence, the XHP strategy can be assumed to be effective for various Mg-based alloying systems. However, as shown in the following, important limitations have to be considered regarding the corrosive environment.

First, we evaluate the influence of the buffering media. Figure 4 shows the ratio of released hydrogen in Tris- and $\mathrm{CO}_{2}$-buffered SBF $\left(\mathrm{H}_{2}\right.$ (Tris)/ $\mathrm{H}_{2}\left(\mathrm{CO}_{2}\right)$ ) at $250 \mathrm{~h}$ of immersion for HP and XHP $\mathrm{Mg}$, and the Y-containing alloys $\mathrm{WE} 43^{26}$ and WZ21. ${ }^{27}$ Data for the modified alloy XHP ZX10 (MgZn1Ca0.3) are also included; the design strategy of this alloy will be discussed in detail in the next section. Changing from $\mathrm{CO}_{2}$ buffer to the organic compound Tris results in an enormous increase in the degradation rate. Such effect of organic buffering agents is well known for various Mg alloys ${ }^{24,28,29}$ but for ZX50, in both conditions HP and XHP, it is extraordinarily pronounced (note that CP ZX50 behaves similar but is not further considered because of its high degradation rate already in $\mathrm{CO}_{2}$-buffered SBF). Obviously, the highZn-containing alloys react very sensitively to the presence of the organic buffer agent. The degradation of HP and XHP ZX50 in Tris is extremely fast and could not be measured properly in our test device. Compared to ZX50, the Y-containing alloys WE43 and ZW21 show a significantly lower but still 


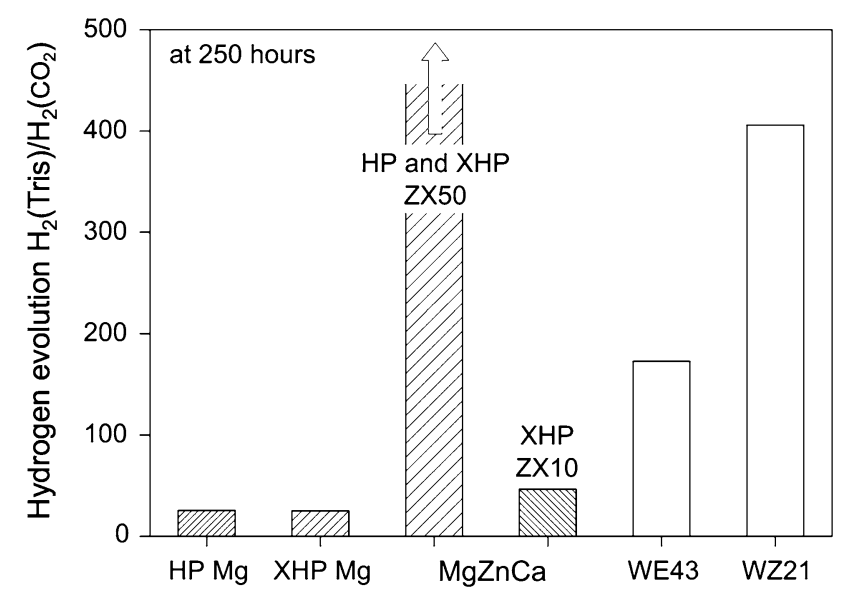

Fig. 4. Ratio of released hydrogen in Tris- and $\mathrm{CO}_{2}$-buffered SBF at $250 \mathrm{~h}$ of immersion. Pure $\mathrm{Mg}$ shows only moderate dependency on the buffer. Stronger dependence is observed for the RE-containing alloys WE43 and WZ21. For HP ZX50 and XHP ZX50, the degradation in Tris-buffered SBF is extremely high and too fast to be measured properly. A reduction of the $\mathrm{Zn}$ content reduces the dependency on the buffer very strongly, as demonstrated for the alloy ZX10.

considerable acceleration of the degradation, whereas pure $\mathrm{Mg}$ exhibits only moderate dependency on the buffer.

The strong acceleration in Tris-buffered SBF is accompanied by a change in the character of the corrosion morphology (Fig. 5). For the alloys in $\mathrm{CO}_{2^{-}}$ buffered SBF, a very homogeneous degradation can be noticed, whereas in Tris-SBF, a distinct localized corrosion attack is observed, and the local attack is most pronounced for the fast-degrading alloys ZX50. However, such change in the degradation morphology does not take place in unalloyed Mg. Furthermore, only very weak localized attack is notable on the alloy XHP ZX10. These findings suggest a strong influence of the alloy's chemical composition on the degradation susceptibility in specific environments.

Recently, several studies suggested that SBF with $\mathrm{CO}_{2}$ buffer simulates the in vivo situation better than organic buffer agents like Tris. ${ }^{24,30,31}$ However, it has become apparent that this is not the case for the high-Zn containing ZX50 alloys. Unpublished immersion tests in protein-containing environments and a 3-month animal test performed by our industrial partner have demonstrated that this alloying system degrades significantly faster than when immersed in $\mathrm{CO}_{2}$-buffered SBF. Clearly, this result puts into question whether $\mathrm{CO}_{2}$ really mimics the in vivo situation, as it was stated in Refs. 24, 29, and 32 but also it encouraged us to modify our design concept toward $\mathrm{Mg}-\mathrm{Zn}-\mathrm{Ca}$ alloys with lower $\mathrm{Zn}$ content, as discussed in the next section.

\section{ALLOY ZX10-CHOICE OF Zn CONTENT}

Recently, several studies considered the influence of the $\mathrm{Zn}$ content in $\mathrm{Mg}-\mathrm{Zn}-(\mathrm{Ca})$ alloys on the corrosion behavior in various environments. ${ }^{16,33-38}$ They all emphasize that well-balanced $\mathrm{Zn}$ and $\mathrm{Ca}$ contents are required to avoid the formation of noble microcathodic IMPs. In particular, Bakhsheshi-Rad et al. ${ }^{16,35}$ pointed out that a too high $\mathrm{Zn}$ content is detrimental because of the formation of high amounts of $\mathrm{Mg}_{6} \mathrm{Zn}_{3} \mathrm{Ca}_{2}$ and $\mathrm{Mg}_{51} \mathrm{Ca}_{20}$. Consequently, reduction of the $\mathrm{Zn}$ content might be an effective recipe for achieving better biocorrosion resistance. Such a simple procedure, however, would result in significant loss in strength because of reduced solid-solution hardening. From the data in Ref. 4, the solid-solution hardening of $\mathrm{Zn}$ can easily be calculated to be roughly $20 \mathrm{MPa} / \mathrm{wt} . \%$, and thus, a reduction of the $\mathrm{Zn}$-content from $5 \%$ to $1 \%$ would result in an undesired loss in yield strength of about $80 \mathrm{MPa}$. Hence, further measures have to be taken to compensate the reduced solid-solution hardening. According to Refs. 39 and 40, the HallPetch coefficient for fine-grained $\mathrm{Mg}$ alloys is about $5 \mathrm{MPa} \mathrm{mm}{ }^{1 / 2}$. Accordingly, a reduction in grain size from $4 \mu \mathrm{m}$ (grain size of CP ZX50 used in Ref. 13) to $1 \mu \mathrm{m}$ would lead to an increase in yield strength of roughly $80 \mathrm{MPa}$. From these simple calculations, it becomes evident that fine-grained microstructures $(D<5 \mu \mathrm{m})$ are required to keep the yield strength at the desired high level, i.e., above $200 \mathrm{MPa}$.

The strategy for achieving very fine grains is based on the assumption that intermetallic particles present in the alloy during hot forming, in our case extrusion, might act as obstacles against grain growth according to Zener. ${ }^{41}$ However, with respect to the biocorrosion performance we need to ensure that such IMPs do not act as cathodic sites. Südholz et al. $^{42}$ investigated relevant IMPs and found all to be cathodic to $\mathrm{Mg}$, with the exception of $\mathrm{Mg}_{2} \mathrm{Ca}$. This IMP exhibits some solubility for $\mathrm{Zn}$ what further allows us to adjust its electrochemical potential. As demonstrated by Cha et al., ${ }^{34}$ the addition of $\mathrm{Zn}$ to $\mathrm{Mg}_{2} \mathrm{Ca}$ shifts the open circuit potential of $(\mathrm{Mg}, \mathrm{Zn})_{2} \mathrm{Ca}$ up to that of the $\mathrm{Mg}$ matrix, which prevents selective corrosion and induces uniform corrosion.

Figure 6a illustrates the constitution of $\mathrm{Mg}-\mathrm{Zn}-$ Ca alloys at $300^{\circ} \mathrm{C}$, i.e., the temperature chosen for the hot-forming procedure (see the "Methods" section). Because the intention is to avoid the formation of the ternary $\mathrm{Mg}_{6} \mathrm{Zn}_{3} \mathrm{Ca}_{2}$ phase, the $\mathrm{Zn}$ content must be kept below $\sim 1.0 \mathrm{wt} . \%$. To benefit from some solid-solution hardening, we chose $1 \mathrm{wt} . \% \mathrm{Zn}$ and further evaluated the optimal Ca content. First, we considered the grain-refining effect of $\mathrm{Mg}_{2} \mathrm{Ca}$ particles. Their Zener pinning pressure increases with the volume fraction and the reduction of particle size, restricting the matrix grain size to a critical maximum (Zener limit). ${ }^{43}$ Because the volume fraction increases proportionally with the Ca content, a high Ca content would be beneficial. However, to create a very fine particle size, we need to apply a solution treatment prior to the extrusion process, followed by an ageing procedure below or at 

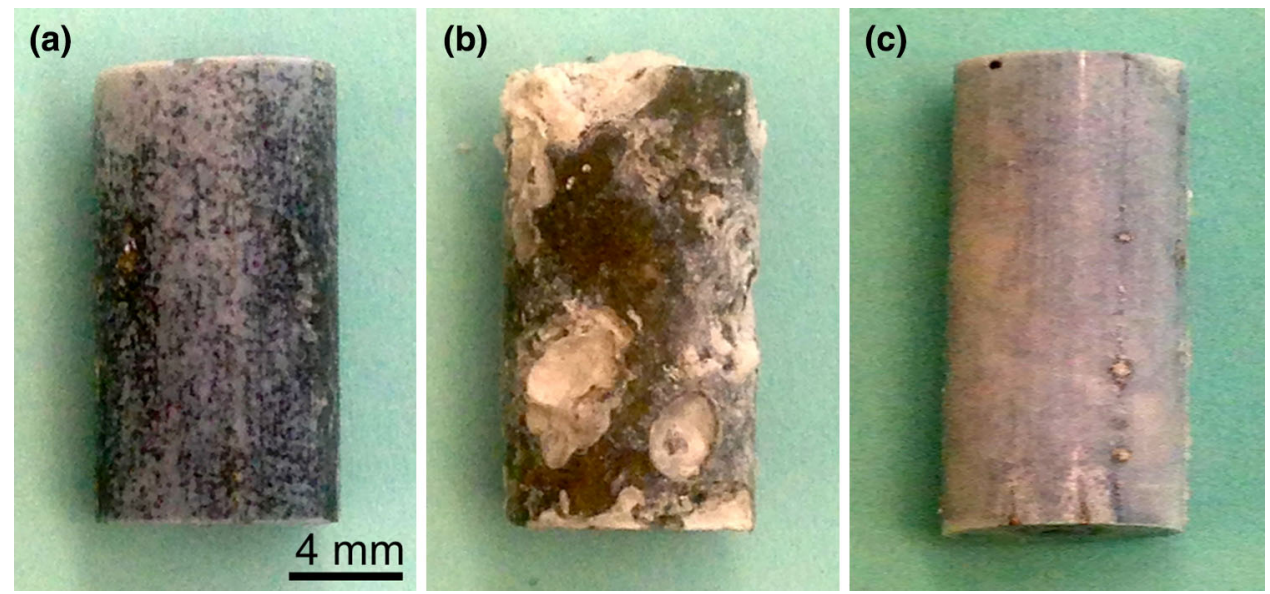

Fig. 5. Surface topography of samples after immersion in SBF. (a) XHP ZX50 shows no local corrosion attack after 2 weeks of immersion in $\mathrm{CO}_{2}$-buffered SBF and (b) massive localized attack in Tris-buffered SBF already after 3 days. (c) No indication of local corrosion attack is visible for XHP ZX10 after 2 weeks of immersion in Tris-buffered SBF.

the hot-forming temperature (see the "Methods" section). The insert in Fig. $6 \mathrm{~b}$ shows the width of the solution-treatment window $\Delta T_{\mathrm{ST}}(\mathrm{Zn}$ and $\mathrm{Ca}$ are completely dissolved in $\mathrm{Mg}$ and the solidus temperature is still not reached, see also Fig. $6 \mathrm{~b}$ ) at a $\mathrm{Zn}$ content of 1 wt.\%. Obviously, with respect to process reliability, the Ca content must be kept significantly below 0.4 wt. $\%$. A compromise of 0.3 wt. $\% \mathrm{Ca}$ has proven to be favorable. The constitution of the $\mathrm{Zn}$ lean alloy MgZn1Ca0.3 (ZX10) is shown in Fig. $6 \mathrm{~b}$. As required, only the $\mathrm{Mg}_{2} \mathrm{Ca}$ phase is present at the processing temperature of $300^{\circ} \mathrm{C}$. According to its Zener drag effect, the resulting grain size stays at low levels, i.e., $D \approx 2 \mu \mathrm{m}$ (for extrusion parameters, see the "Methods" section). The corresponding mechanical properties of this newly developed alloy, exhibiting the lowest content of alloying elements of all technical $\mathrm{Mg}$ alloys, are as follows. In tension: yield strength TYS $=240 \mathrm{MPa}$, ultimate tensile strength UTS $=255 \mathrm{MPa}$, and elongation to fracture $A=27 \%$; in compression: CYS $=205 \mathrm{MPa}$, $\mathrm{UCS}=245 \mathrm{MPa}$, and $A=13 \%$. These values show that the alloy features not only high strength and good ductility but also low mechanical anisotropy.

Interestingly, our design strategy is comparable to HSLA steels, where low amounts of alloying elements are intended to produce a very fine dispersion of carbides, which increase the material's strength by refining the grain size as a result of the effect of particles on dynamic recrystallization and grain growth. ${ }^{44}$

The good mechanical properties of the alloy XHP ZX10 are accompanied by excellent biocorrosion behavior. Figure 7 illustrates its in vivo degradation performance compared to CP ZX50 after 12 weeks of implantation time (rat femur implantation of pins with $1.6 \mathrm{~mm}$ diameter). The fast corroding CP ZX50 has completely degraded, ${ }^{13}$ while the newly developed XHP ZX10 exhibits the desired slow and homogeneous degradation. It is important to note that no hydrogen bubbles can be observed. Apparently, the living organism was able to absorb the generated low amount of hydrogen; this fact is of high relevance from a medical point of view. Details of the progress of biodegradation and the corresponding bone and tissue response will be reported elsewhere.

\section{SUMMARY AND CONCLUSIONS}

We have reported on the development of a biocompatible, HSLA magnesium alloy for use as biodegradable implant material. Following the pathway from a high-Zn containing alloy (ZX50) and reducing the impurities of corrosion-provoking elements (such as $\mathrm{Fe}, \mathrm{Cu}, \mathrm{Ni}, \mathrm{Co}, \mathrm{Mn}$, and $\mathrm{Si}$ ) down to the $<3 \mathrm{ppm}$ level, we developed a new XHP Mg alloy (ZX10, MgZn1Ca0.3 in wt.\% or $\mathrm{Mg}_{99.45} \mathrm{Zn}_{0.35} \mathrm{Ca}_{0.2}$ in at.\%), which contains only 0.55 at.\% of alloying elements. The reduction of the $\mathrm{Zn}$ content generates after processing the formation of a $(\mathrm{Mg}, \mathrm{Zn})_{2} \mathrm{Ca}$ phase, which can be homogeneously distributed as nanometer-sized IMPs in the $\mathrm{Mg}$ matrix.

The new Mg alloy ZX10 shows a very fine microstructure for a technical wrought alloy, with a matrix grain size of $\approx 2 \mu \mathrm{m}$. This small grain size generates outstanding mechanical properties, such as high strength and simultaneously high ductility, as well as low mechanical anisotropy. The $(\mathrm{Mg}, \mathrm{Zn})_{2} \mathrm{Ca}$ IMPs are less noble than the matrix and thus can act as anodic sites. As a consequence, the alloy degrades homogeneously in in vivo studies (rat femur implantation) and at the desired low level without any hydrogen bubble formation. The superior in vivo degradation performance and mechanical properties make the ZX10 alloy the most ideal technical alloy for biodegradable implant applications. 
(a)

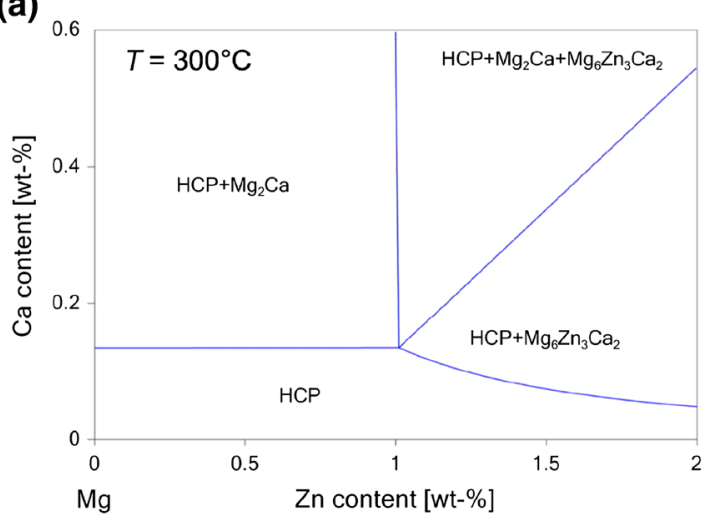

(b)

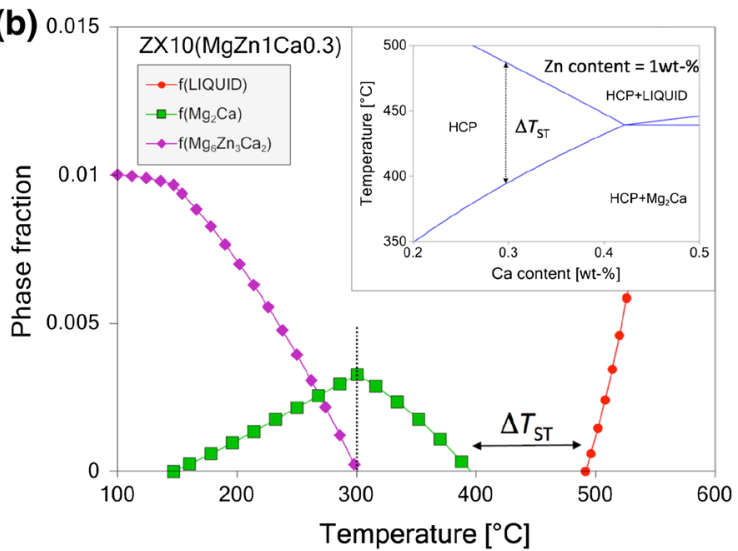

Fig. 6. (a) Isothermal section of the $\mathrm{Mg}-\mathrm{Zn}-\mathrm{Ca}$ system at $300^{\circ} \mathrm{C}$. (b) Constitution of the alloy $\mathrm{MgZn} 1 \mathrm{Ca} 0.3(\mathrm{ZX} 10)$; at $300^{\circ} \mathrm{C}$, only the $\mathrm{Mg}{ }_{2} \mathrm{Ca}$ phase is present; the insert illustrates the influence of the Ca content on the width of the solution-treatment window $\Delta T_{\mathrm{ST}}$.
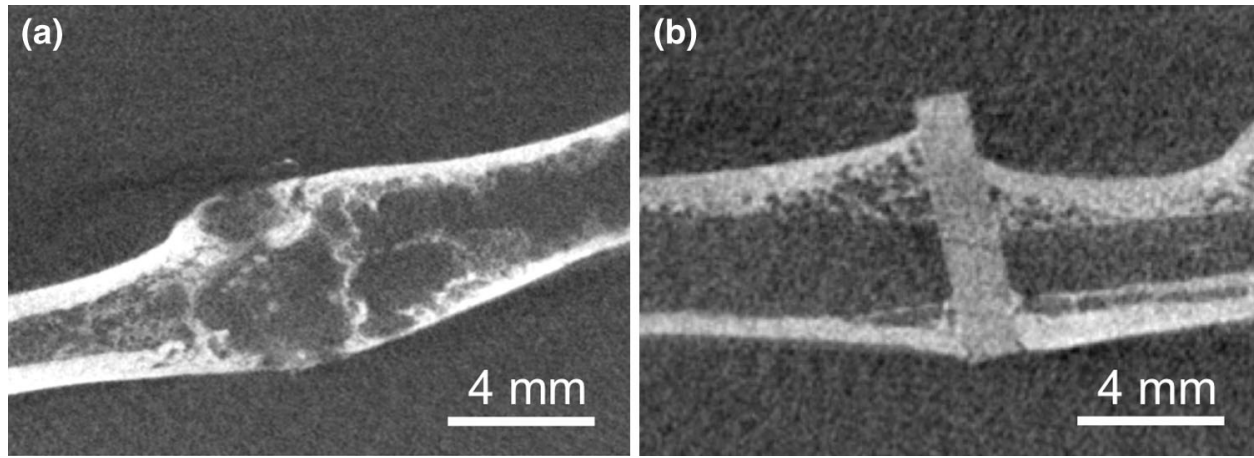

Fig. 7. $\mu \mathrm{CT}$ reconstructions (two-dimensional slices) of Mg pins implanted into the femur of Sprague-Dawley rats 12 weeks after operation. Whereas the 1st-generation alloy CP ZX50 has completely degraded and severe irritation of the bone is observed (a), ${ }^{13}$ only slight homogeneous degradation is noticed for XHP ZX10 (b). Furthermore, no hydrogen bubbles are observed in the case of the newly developed XHP ZX10 alloy.

\section{METHODS}

\section{Preparation of Mg Alloys}

For the production of HP ZX50, high-purity Mg (99.98\%), Ca (99.0\%), and Zn (99.99\%) were used, while for the XHP alloys ZX50 and ZX10, distilled ultrapure $\mathrm{Mg}$ (99.999\%), ${ }^{21} \mathrm{Ca}$ (99.99\%), and $\mathrm{Zn}$ (99.999\%) were synthesized in a graphite crucible under a protective gas mixture at $750^{\circ} \mathrm{C}$. Subsequently, the melt was poured into a conical graphite mold (average diameter $55 \mathrm{~mm}$, height $\approx 150 \mathrm{~mm}$ ), which was water cooled at the bottom to force directional solidification to avoid shrinkage cavities. Afterward, the billets were homogenized (ZX50 alloys: $350^{\circ} \mathrm{C} / 12 \mathrm{~h}$; ZX10 alloy: $350^{\circ} \mathrm{C} / 12 \mathrm{~h}$ plus $450^{\circ} \mathrm{C} /$ $8 \mathrm{~h}$ ) followed by cooling with pressurized air. The chemical compositions of the samples were determined by glow discharge mass spectrometry.

\section{Extrusion Procedure}

The homogenized alloys were machined to billets, measuring $50 \mathrm{~mm}$ in diameter and $120 \mathrm{~mm}$ in length. For XHP ZX10, the billet was aged at $250^{\circ} \mathrm{C}$ for $30 \mathrm{~min}$ to create fine and homogeneously distributed intermetallic particles prior to the extrusion process. Afterward, the billet was heated to $300^{\circ} \mathrm{C}$ and indirect extrusion was performed at a ram speed of $0.15 \mathrm{~mm} / \mathrm{s}$ to a rod profile with a diameter of $10 \mathrm{~mm}$, corresponding to an extrusion ratio of 25:1. Cooling with pressurized air was applied at the exit side of the extrusion press. For the ZX50 alloys, the extrusion to $10 \mathrm{~mm}$ diameter was performed in the direct mode at $325^{\circ} \mathrm{C}$.

\section{Immersion Tests}

The degradation was measured by the hydrogen evolution method ${ }^{23}$ and evaluated using an in-house improved testing setup. ${ }^{24}$ The device exhibits a high gas volume resolution and was especially designed for slow degrading materials; it accounts also for the daily atmospheric pressure fluctuations and gas dissolution. The specimen sizes were used with surface areas in the range of $259 \pm 1 \mathrm{~mm}^{2}$ to $626 \pm 6.7 \mathrm{~mm}^{2}$. Three specimens per batch were tested and their mean hydrogen evolution was evaluated to $\mathrm{mL} / \mathrm{cm}^{2}$. All data points were corrected by the atmospheric pressure and the gas dissolution. The ion concentration of the SBF used for the 
immersion tests is described in Ref. 27; either $\mathrm{CO}_{2}$ (99.90 vol.\%) or Tris was used as buffer. During the degradation test, the $\mathrm{pH}$ was set at $7.45 \pm 0.017$ with a temperature of $36.9 \pm 0.30^{\circ} \mathrm{C}$ for 2 weeks. The samples were ground on abrasive $\mathrm{SiC}$ paper of granularity 4000 . Just before immersion, they were polished on a $1 \mu \mathrm{m}$ polishing cloth, cleaned in an ultrasonic bath using isopropanol, and dried in hot air.

\section{ACKNOWLEDGEMENTS}

The authors appreciate the support of the K-project OptiBioMat (Development and optimization of biocompatible metallic materials); FFG-COMET program, Austria; and the Laura Bassi Center of Expertise Bioresorbable Implants for Children (BRIC), FFG, Austria. We are most grateful to DePuy Synthes Biomaterials, Synthes GmbH, Switzerland, for the valuable scientific support; special thanks go to Dr. Thomas Imwinkelried.

\section{REFERENCES}

1. F. Witte, N. Hort, C. Vogt, S. Cohen, K.U. Kainer, and R. Willumeit, Curr. Opin. Solid State Mater. Sci. 12, 63 (2008).

2. M.P. Staiger, A.M. Pietak, J. Huadmai, and G. Dias, Biomaterials 27, 1728 (2006).

3. B. Zberg, P.J. Uggowitzer, and J.F. Löffler, Nat. Mater. 8, 887 (2009).

4. A.C. Hänzi, A. Sologubenko, P. Gunde, M. Schinhammer, and P.J. Uggowitzer, Philos. Mag. Lett. 92, 417 (2012).

5. H. Tapiero and K.D. Tew, Biomed. Pharmacother. 57, 399 (2003).

6. M. Stefanidou, C. Maravelias, A. Dona, and C. Spiliopoulou, Arch. Toxicol. 80, 1 (2006).

7. P. Gunde, A.C. Hänzi, A.S. Sologubenko, and P.J. Uggowitzer, Mater. Sci. Eng. A 528, 1047 (2011).

8. A.C. Hänzi, F.H. Dalla Torre, A.S. Sologubenko, P. Gunde, R. Schmid-Fetzer, M. Kuehlein, J.F. Löffler, and P.J. Uggowitzer, Philos. Mag. Lett. 89, 377 (2009).

9. J. Koike, Mater. Sci. Forum 449, 665 (2004).

10. J. Koike, T. Kobayashi, T. Mukai, H. Watanabe, M. Suzuki, K. Maruyama, and K. Higashi, Acta Mater. 51, 2055 (2003).

11. C.L. Mendis, K. Oh-ishi, Y. Kawamura, T. Honma, S. Kamado, and K. Hono, Acta Mater. 57, 749 (2009).

12. T. Homma, C.L. Mendis, K. Hono, and S. Kamado, Mater. Sci. Eng. A 527, 2356 (2010).

13. T. Kraus, S.F. Fischerauer, A.C. Hänzi, P.J. Uggowitzer, J.F. Löffler, and A.M. Weinberg, Acta Biomater. 8, 1230 (2012).

14. K. Pichler, S.F. Fischerauer, P. Ferlic, E. Martinelli, H.P. Brezinsek, P.J. Uggowitzer, J.F. Löfler, and A.M. Weinberg, $J O M$, this issue.

15. M. Liu, P.J. Uggowitzer, A.V. Nagasekhar, P. Schmutz, M. Easton, G.-L. Song, and A. Atrens, Corros. Sci. 51, 602 (2009).

16. H.R. Bakhsheshi-Rad, M.R. Abdul-Kadir, M.H. Idris, and S. Farahany, Corros. Sci. 64, 184 (2012).

17. J.D. Hanawalt, C.E. Nelson, and J.A. Peloubet, Trans. AIME 147, 273 (1942).
18. J. Hillis and R.W. Murray (Paper presented at SDCE 14th International Die Casting Congress and Exposition, Toronto, Canada, 1987), Paper No. G-T87-003.

19. G.L. Song and A. Atrens, Adv. Eng. Mater. 1, 11 (1999).

20. G.L. Song and A. Atrens, Adv. Eng. Mater. 5, 837 (2003).

21. J.F. Löffler, P.J. Uggowitzer, C. Wegmann, M. Becker, and H.K. Feichtinger, European Patent Application PCT/EP 2013/000131-WO2013/107644 (2012-2013).

22. CompuTherm LLC, Pandat software package for calculating phase diagrams and thermodynamic properties of multicomponent alloys, Madison, WI 53719 USA. http://www. computherm.com/.

23. G. Song, A. Atrens, and D.H. StJohn (Paper presented at the Magnesium Technology Conference at TMS, New Orleans, LA, 2001), p. 255.

24. M. Schinhammer, J. Hofstetter, C. Wegmann, F. Moszner, J.F. Löffler, and P.J. Uggowitzer, Adv. Eng. Mater. 15, 434 (2013).

25. F. Cao, Z. Shi, J. Hofstetter, P.J. Uggowitzer, G. Song, M. Liu, and A. Atrens, Corros. Sci. 75, 78 (2013).

26. H. Kalb, A. Rzany, and B. Hensel, Corros. Sci. 57, 122 (2012).

27. A.C. Hänzi, I. Gerber, M. Schinhammer, J.F. Löffler, and P.J. Uggowitzer, Acta Biomater. 6, 1824 (2010).

28. A. Yamamoto and S. Hiromoto, Mater. Sci. Eng. C 29, 1559 (2009).

29. N.T. Kirkland, N. Birbilis, and M.P. Staiger, Acta Biomater. 8, 925 (2012).

30. N.T. Kirkland, J. Waterman, N. Birbilis, G. Dias, T. Woodfield, R. Hartshorn, and M.P. Staiger, J. Mater. Sci. Mater. Med. 23, 283 (2012).

31. N.I. Zainal Abidin, A.D. Atrens, D. Martin, and A. Atrens, Corros. Sci. 53, 3542 (2011).

32. N.I. Zainal Abidin, B. Rolfe, H. Owen, J. Malisano, D. Martin, J. Hofstetter, P.J. Uggowitzer, and A. Atrens, Corros. Sci. 75, 354 (2013).

33. Y. Song, E.-H. Han, D. Shan, C.D. Yim, and B.S. You, Corros. Sci. 60, 238 (2012).

34. P.-R. Cha, H.-S. Han, G.-F. Yang, Y.-C. Kim, K.-H. Hong, S.C. Lee, J.-Y. Jung, J.-P. Ahn, Y.-Y. Kim, S.-Y. Cho, J.Y. Byun, K.-S. Lee, S.-J. Yang, and H.-K. Seok, Scientif. Rep. 3 (2013). doi:10.1038/srep02367.

35. H.R. Bakhsheshi-Rad, M.H. Idris, M.R. Abdul-Kadir, S. Farahany, and M.Y. Yahya, Appl. Mech. Mater. 121, 568 (2012).

36. E. Zhang and L. Yang, Mater. Sci. Eng. A 497, 111 (2008).

37. H. Du, Z. Wei, X. Liu, and E. Zhang, Mater. Chem. Phys. 125,568 (2011).

38. N.T. Kirkland, N. Birbilis, J. Walker, T. Woodfield, G.J. Dias, and M.P. Staiger, J. Biomed. Mater. Res. B Appl. Biomater. 95, 91 (2010).

39. D.V. Wilson and J.A. Chapman, Philos. Mag. 8, 1543 (1963).

40. M.R. Barnett, Z. Keshavarz, A.G. Beer, and D. Atwell, Acta Mater. 52, 5093 (2004).

41. G. Gottstein and L.S. Shvindlerman, Grain Boundary Migration in Metals: Thermodynamics, Kinetics, Applications (Boca Raton, FL: CRC Press, Taylor \& Francis Group, 2010).

42. A.D. Südholz, N.T. Kirkland, R.G. Buchheit, and N. Birbilis, Electrochem. Solid-State Lett. 14, C5 (2011).

43. P.A. Manohar, M. Ferry, and T. Chandra, ISIJ Int. 38, 913 (1998).

44. J.D. L'Ecuyer and G. L'Espérance, Acta Metall. 37, 1023 (1989). 